\title{
Virtual Reality Training Applications for the Mining Industry
}

\author{
Etienne van Wyk \\ Tshwane University of Technology \\ vanwykea@tut.ac.za
}

\author{
Ruth de Villiers \\ University of South Africa \\ dvillmr@unisa.ac.za
}

\begin{abstract}
Virtual reality is a rapidly growing technology which utilises the ever-increasing power of computers to simulate real-world and imaginary environments and situations with a high degree of realism and interactiveness.

Safety in the South African mining industry is a vital issue. On average, one worker dies every working day, and about 16 are injured in mine-related accidents. Inadequate or insufficient training is often cited as a root cause for many mining fatalities. However, training outside the direct working environment provides only limited real-life opportunities and may fail to make a significant impact within the tense working environment itself. Virtual reality-based training tools can, by contrast, provide simulated exposure to real-world working conditions without the associated risks.
\end{abstract}

This paper discusses contextual requirements and constraints for virtual reality application development, applied to safety training in mines. The results of the contextual analysis were applied to the design and development of several prototypes of VR training systems. The paper also reports on how realism can be enhanced in simulation training systems.

\section{Categories and Subject Descriptors:}

H.5.1 [Information Interfaces and Presentation]: Multimedia Information Systems - Artificial, augmented, and virtual realities;

K.3.1 [Computers and Education]: Computer Uses in Education - computer-assisted instruction;

K.4.1 [Computers and Society]: Public Policy Issues - human safety;

I.3.7 [Computer Graphics]:Three-Dimensional Graphics and Realism - virtual reality;

I.3.8 [Computer Graphics]:Applications.

Keywords: virtual reality, safety training, realism, mining training applications.

\section{Introduction}

Virtual reality, popularly referred to as VR, is a rapidly growing technology which utilises the ever-increasing power of computers to simulate real-world and imaginary environments and situations with a high degree of realism and interactiveness.

Copyright $\odot 2009$ by the Association for Computing Machinery, Inc.

Permission to make digital or hard copies of part or all of this work for personal or classroom use is granted without fee provided that copies are not made or distributed for commercial advantage and that copies bear this notice and the full citation on the first page. Copyrights for components of this work owned by others than ACM must be honored. Abstracting with credit is permitted. To copy otherwise, to republish, to post on servers, or to redistribute to lists, requires prior specific permission and/or a fee. Request permissions from Permissions Dept, ACM Inc., fax +1 (212) 869-0481 or e-mail permissions@acm.org.

Afrigraph 2009, Pretoria, South Africa, February 04 - 06, 2009.

(c) 2009 ACM 978-1-60558-428-7/09/0002 $\$ 5.00$
Users can interact with the virtual worlds via a variety of hardware devices (e.g. joysticks and data gloves), and the impression of actually being in the virtual world (immersion) can be created and enhanced by special optical and audio devices (e.g. head-mounted displays and 3D sound).

Virtual reality originally denoted a fully immersive system, although it has since been used to describe systems lacking cybergloves and head-mounted displays. Non-immersive virtual reality uses a computer monitor and the user interacts with the system using a joystick, mouse or keyboard. VR systems are real-time computer simulations of the real world, in which visual realism, object behaviour and user interaction are essential elements [Denby and Schofield 1999; Orr et al. 2002].

Modern simulation systems range from tactile systems that physically represent the real world through to purely computergenerated visualisations. These computer-generated, threedimensional, artificial worlds are commonly referred to as Virtual Environments (VE), and in many cases users are able to interact with the data and images that are presented by these computer-based visual systems.

In a mining context, a primary aim of developing virtual environments is to allow mine personnel to practise and experience mine situations, activities and processes that can be encountered in the day to day operations at a mining site. Safe and efficient planning and production are fundamental to profitable mine operations and VR provides an intuitive means of exploring the diverse and disparate information associated with mining processes.

\section{Safety at South African mines}

Safety performance data for South African mines is published by the Mine Health and Safety Inspectorate. There were 3808 underground reportable injuries in 2003, and 446 surface reportable injuries. In total, 264 people died in mining accidents in 2003, with 293 and 288 fatalities in 2002 and 2001 respectively. The Inspectorate also lists major accidents where four or more people were killed. There has been an average of seven such major mining accidents a year over the last 20 years [Department of Mineral and Energy 2006].

Traditionally, research into reducing subsurface mining accidents has concentrated on reducing fall of ground (FOG) accidents by providing improved support units and systems and improved mining layout design [Squelch 2000]. An additional approach promoted in the Mine Health \& Safety Act 29 of 1996 is, however, to improve the level and effectiveness of training given to underground workers. In the context of underground accidents this training emphasis lies in the area of hazard identification and associated remedial safety action. 
In South Africa, the Mine Health and Safety Act [1996] has identified the creation of a culture of health and safety as one of its objectives. This objective is supported by a number of statutory provisions which require employee participation, instruction and training of employees, risk management, disclosure of information to employees and the employee's right to leave a work place which poses a serious danger to health and safety. The Act requires the employer to consider, as far as reasonably practicable, an employee's training and capabilities in respect of health and safety before assigning a task to that employee. In addition, the employer is required to provide, as far as reasonably practicable, employees with any information, instruction, training or supervision that is necessary to enable them to perform their work safely and without risk to health [Le Roux 2005].

Whilst employers are primarily responsible for providing safe and healthy workplaces, the Department of Minerals and Energy is the lead agent in promoting, monitoring and enforcing legislation and initiating prosecution in terms of the Mine Health and Safety Act of 1996. Guidelines regarding the enforcement of the Act were released in January 2005 by the South African Government. This document contains instructions enforcing compliance with any provisions of the Act and makes provision for fines and prosecution of offenders [Department of Minerals and Energy 2005].

Unfortunately, while new training rules and regulations have been enacted, many training tools and techniques are not as effective as they could be in providing safety training. Recent meetings of Safety, Health and Environment managers at South African mines indicate that the mining community needs improved training tools [Baker 2005; Moldenhauer 2004; Wenhold 2005]. During interviews conducted at two large South African mines, the mine managers specifically requested help for developing new safety training methods. They mentioned the importance of effective training and the need for improved and updated mine safety training material [Lubbe 2004; Stander 2004].

In the South African Mining Industry, current training methods rely on repetitive classroom style learning with some instruction being given in a physical mock-up of an underground workplace followed by on the job training. If it is assumed that current methods are not adequate for training workers to operate safely underground, then a viable alternative or additional method is required.

\section{Virtual Reality in safety training}

VR has evolved considerably over the last two decades. "Although VR is still maturing as a technology, implications for its future as a tool for education, science, medicine and other fields, seem certain" [De Strulle 2004:76]. VR is currently being used and investigated for providing training solutions in a variety of industries and fields such as military, medical, power generation and aircraft. VR has a number of features that appear well suited to e-training within mining environments and, in particular, for hazard recognition and associated remedial safety action. The primary features of relevance are: the facility to expose trainees to simulated hazardous situations without putting them in any actual danger; the facility to simulate hazardous situations more frequently than would be encountered in the real world; and the simulation of situations that have not previously occurred but which could be encountered in the industry [Van Wyk and Callaghan 2007].

Meetings with various role players in the mining industry, as well as interviews with mine safety, health and environmental (SHE) representatives, identified the following training issues:

- The safety of untrained employees in on-the-job training.

- A time constraint due to productivity pressures.

- Classroom-based training traditionally did not provide sufficient interactivity.

- Language barriers.

- Monitoring trainee progress.

Mining in the 21st Century is a high-technology industry that strives to reduce risk and improve safety through the use of improved processes and procedures. This risk reduction process is aligned with the innovative use of technologies often developed for other industries. Interactive computer-based visualisation systems and their content are an example.

To date, mining has placed the emphasis on representing synthetic virtual models of the mine environment. In particular, this approach has proved successful with respect to producing virtual mine training environments [Schofield et al. 2001; Stothard 2001, 2007; Schmid 2003; Unger and Mallet 2004; Squelch 2001; Van Wyk 2006]. Legislated mine training requirements have also driven much simulation development yet take-up and acceptance by the industry is still very slow. This slow acceptance is occurring despite implementations of interactive training simulations such as those described by Unger and Mallet [2007], and despite the concept of VR being introduced in the mining industry in the nineties when low cost simulators were discussed by Bise [1997] and Denby et al. [1998]. Moreover, Squelch [2001] described simulations that represented high risk environments where the content was mainly synthetic and which also contained real-world information such as video clips, photos and web based data. By contrast to this reluctance, other industries such as aviation, oil and gas and medicine have embraced the technology [Stothard 2001].

Stothard et al. [2008] propose a taxonomy that broadly classifies the wide range of interactive computer-based visualisation technologies that are available to the mining industry. The taxonomy is based on the early work of Milgram and Kishino [1994]. However, it includes modifications to cover subsequent technology advances (See Table 1).

Milgram and Kishino [1994] realised that while virtual environments mimic the properties and laws of the real world and beyond, what is often overlooked is that virtual reality can be associated with other environments. That is, virtual worlds can be augmented with real images and data. For mining operations this presents a powerful tool from both an operations and training perspective where synthetic images derived from predictive data may be combined and overlaid upon real world images and experience. 


\begin{tabular}{|c|c|c|c|c|c|c|}
\hline & Class Description & $\begin{array}{l}\text { View } \\
\text { Window } \\
\text { on World } \\
\text { (WOW) }\end{array}$ & $\begin{array}{l}\text { Large } \\
\text { Screen } \\
\text { Displays }\end{array}$ & $\begin{array}{l}\text { Real World } \\
\text { Content } \\
\text { Optical or } \\
\text { Video }\end{array}$ & $\begin{array}{l}\text { Immersive. } \\
\text { Full, Semi, } \\
\text { Non }\end{array}$ & $\begin{array}{l}\text { Individual or } \\
\text { group use }\end{array}$ \\
\hline Class 1 & $\begin{array}{l}\text { Monitor based video displays with } \\
\text { capability to show video and computer } \\
\text { generated graphics simultaneously. }\end{array}$ & Yes & No & Video & Non & Individual \\
\hline Class 2 & $\begin{array}{l}\text { Head mounted video displays with } \\
\text { capability to show video and computer } \\
\text { generated graphics simultaneously. }\end{array}$ & No & No & Video & Full & Individual \\
\hline Class 3 & $\begin{array}{l}\text { Head mounted video displays with } \\
\text { capability to see through to real world and } \\
\text { show computer generated graphics } \\
\text { simultaneously. }\end{array}$ & No & No & Optical & Full & Individual \\
\hline Class 4 & $\begin{array}{l}\text { Head mounted displays with capability to } \\
\text { show video of real world and computer } \\
\text { generated graphics simultaneously. }\end{array}$ & No & No & Video & Full & Individual \\
\hline Class 5 & $\begin{array}{l}\text { Large screen(s), completely graphic display } \\
\text { environments with capability to show } \\
\text { computer generated graphics and video } \\
\text { simultaneously. }\end{array}$ & No & Yes & Video & Full \&Semi & $\begin{array}{l}\text { Individual or } \\
\text { group. }\end{array}$ \\
\hline Class 6 & $\begin{array}{l}\text { Large screen(s), completely graphic } \\
\text { environments that are partially immersive } \\
\text { and use real physical objects or haptic } \\
\text { devices to play a role in the computer } \\
\text { generated scene. }\end{array}$ & No & Yes & Video & Semi & $\begin{array}{l}\text { Individual or } \\
\text { group. }\end{array}$ \\
\hline Class 7 & $\begin{array}{l}\text { Large full surround screen(s), completely } \\
\text { graphic environments that are fully } \\
\text { immersive and use real physical objects or } \\
\text { haptic devices to play a role in the } \\
\text { computer generated scene. }\end{array}$ & No & Yes & Video & Full & $\begin{array}{l}\text { Individual or } \\
\text { group }\end{array}$ \\
\hline Class 8 & $\begin{array}{l}\text { Device with capability to see through to } \\
\text { real world and show computer generated } \\
\text { graphics simultaneously. }\end{array}$ & Yes & No & Optical & Non & $\begin{array}{l}\text { Individual or } \\
\text { very small } \\
\text { group 1-3. }\end{array}$ \\
\hline Class 9 & $\begin{array}{l}\text { Hand held mobile device with capability to } \\
\text { show video of real world and computer } \\
\text { generated graphics simultaneously. }\end{array}$ & Yes & No & Video & Non & $\begin{array}{l}\text { Individual or } \\
\text { very small } \\
\text { group 1-3. }\end{array}$ \\
\hline Class 10 & True Holographic devices. & No & No & Optical & Semi & $\begin{array}{l}\text { Individual or } \\
\text { group }\end{array}$ \\
\hline
\end{tabular}

Table 1. Taxonomy of Interactive Computer-based Visualisation Systems [Stothard et al. 2008]

The taxonomy presents several classes of hybrid display environments as summarised below.

Class 1. Monitor based (non-immersive) video displays - i.e. "window-on-the-world" (WoW) displays - upon which computer generated images are electronically or digitally overlaid. Although the technology for accomplishing such combinations has been around for some time, most notably by means of chroma-keying, practical considerations compel us to be interested particularly in systems in which this is done stereoscopically.

Class 2. Video displays as in Class 1, but using immersive headmounted displays (HMD's), rather than WoW monitors.

Class 3. HMD's equipped with a see-through capability, with which computer generated graphics can be optically superimposed, using half-silvered mirrors, onto directly viewed real-world scenes.

Class 4. Same as 3, but using video, rather than optical, viewing of the "outside" world. The difference between Classes 2 and 4 
is that with 4 the displayed world should correspond orthoscopically with the immediate outside real world, thereby

Class 5. Completely graphic display environments, completely immersive, partially immersive or otherwise, to which video "reality" is added.

Class 6. Completely graphic but partially immersive environments (e.g. large screen displays) in which real physical objects in the user's environment play a role in (or interfere with) the computer generated scene, such as in reaching in and "grabbing" something with one's own hand.

Class 7. Large full surround screen(s), displaying completely graphic environments that are fully immersive and use real physical objects or haptic devices to play a role in the computer generated scene. Examples of these are CAVE and Visionarium systems and in some cases Domes. These systems are large spaces intended for individual or group experience.

Class 8. Devices with a capability to see through to the real world and show computer generated graphics simultaneously.

Class 9. Hand held mobile devices with capability to show video of real world and computer generated graphics simultaneously.

Class 10. True 3D holographic or hologrammatic representations that mix reality with the real world.

\section{Research Questions}

The study described in the present paper sets out to guide the development of future VR training systems. It aims to answer questions about the real-life tasks and the context that these systems should support, the functionality of such systems and their levels of realism. The primary research questions are:

- What are the contextual requirements and constraints for VR training systems for the mining industry?

- How can realism be enhanced in simulation training?

\section{Research methodology}

Data collection was done in an integrated fashion, using each data collection instrument or session to address several of the aspects requiring investigation. The methods used were:

- Semi-structured interviews with mine managers and safety, health and environment (SHE) managers.

- $\quad$ Structured interviews with mine workers.

- Observations of current training methods at different mines.

- Questionnaires completed by trainees on specific contextual requirements and constraints.

- Observations carried out at several underground mining stope areas to observe miners performing their daily tasks.

- Online questionnaires completed by 223 trainees after completion of the hazard awareness prototype training systems.

The researcher carried out naturalistic observations in an unobtrusive manner, watching participants working underground. Questions were asked to verify the information gathered during the interviews before or after work activities. Photographs and video material were taken whenever possible and where creating a "video see-through" system, analogous with the optical see-through of option 3 .

permissible. Triangulation was used to confirm and synthesize the data collected from multiple sources.

\section{Contextual requirements and constraints}

The first research question aims to investigate the contextual requirements and constraints for VR training systems for the mining industry. The findings are categorised as relating to users, tasks, equipment, environment, and training.

\subsection{Users}

The Department of Minerals and Energy uses the Mining Industry Standard Code of Occupations [Department of Minerals and Energy 2008], listing 1032 job titles in the mining profession. For the purpose of this study only underground mine workers were observed and interviewed, involving mainly the following jobs: Belt Attendant, Miner, Cheesa (Miner's assistant), Rock Drill Operator, Loco Driver, Panel Operator, Shift Supervisor, Team Leader, Stope Timberman and Winch Operator.

A total of 43 structured interviews were conducted with randomly selected workers from 10 Shaft at Impala Platinum Mine. The interviews were conducted by clerks from 10 Shaft in the workers' preferred language and the interviewees' answers were written down on a prepared interview sheet. Analysis of the interview answers yielded the following results:

- The subjects have different cultural backgrounds and speak various languages.

- $\quad$ Some have a very limited understanding of English.

- Ages are between 20 and 60; levels of education vary from Grade 5 to Grade 12.

- The interviewees have various levels of underground mining experience, ranging between 2 years and 25 years.

- Currently, most underground workers are men, but some mines are appointing women in certain of these job positions.

- The majority of the interviewees are confident that they can perform their duties well.

- More than $80 \%$ of the interviewees have never used a computer.

- To determine usage of technology, workers were asked whether they use cell phones and ATM's. More than $80 \%$ answered in the affirmative. Despite their wide range in literacy level and minimal computing experience, they were not afraid of the prospect of computer-based training. In fact, they were of the opinion that they would enjoy it!

It also emerged from the interviews that workers are concerned about safety and the high number of accidents. The researchers noted that the National Union of Mineworkers organised a formal protest march in December 2007 where thousands of mineworkers marched in central Johannesburg, urging management to improve safety conditions. Concern is also raised about the production bonuses offered by certain mines, which might place the emphasis on production at the potential cost of safety. 


\subsection{Tasks and associated hazards}

Many varying tasks within different underground job categories were identified in observation and in discussions with SHE managers and workers. For this study, it was decided to focus on the hazards associated with these tasks from the perspectives of: hazard recognition, hazard identification, and correct procedures in addressing hazards.

Hazards can be classified as generic or job-specific. All the underground workers should be aware of hazards in their workplace, both in the haulage and in the stope area. All of them should be able to identify and fix generic hazards, while jobspecific hazards refer to potentially dangerous conditions that can occur while performing duties of a specific job. For example, a winch operator may encounter various hazardous conditions while working with the winch, which the rock drill operator may not be exposed to, but since the winch cables and snatch blocks are used within the stope area there are some generic winch hazards which all workers should recognise.

Analysis of the data obtained via interviews and observation led to the categorisation of generic hazards into five task groups: Employee actions, Geological conditions, Machinery and equipment, Good house-keeping and Sub-standard conditions. For each of group, workers should be able to recognise particular hazards, correctly identify them and follow the correct procedure in dealing with them.

\subsection{Equipment}

During underground observation, the researcher noted that the equipment used by workers depends on their particular duties. For example, a cheesa might use a pinch bar to make an underground workplace safe by means of barring down loose rocks, whereas the rock drill operator uses a pneumatic or hydraulic rock drill. It was mentioned by SHE managers that specialised training is required for using different tools and equipment.

Workers are required to wear the correct PPE (Personal Protective Equipment), which usually includes a hard hat, overall, boots, ear plugs, cap lamp, battery pack and protective glasses. Not wearing the correct PPE is also a generic hazard.

\subsection{Work environment}

Based on observations, the underground work environment can be described as dirty, dark, wet, noisy, hot, uncomfortable and dangerous. Hazards related to the work environment can include:

- Working in confined areas.

- Working in steeply inclined excavations.

- Handling heavy material and equipment.

- Working in the proximity of moving machinery.

The size of the stope areas, where drilling and blasting occur, varies from one mine to another, but the stopes observed were approximately 27 meters wide with a maximum height of 1.5 meters. The gulley area next to the stope, from which the scraper winch extracts the blasted rock, is about 2.5 meters high, allowing workers to stand upright when not working in the stope. Rock drill operators work in a sitting position while drilling holes for the explosives. Blasted areas are watered down as part of the cleaning process, causing the areas to be wet. Excessive water is hazardous and can lead to slip-and-fall incidents.

With ground falls being the main cause of fatalities in the industry, it is essential to correctly identify different geological conditions, especially after blasting. Conditions such as shear zones, joints and dykes should be supported correctly to prevent falls of ground, and loose rocks should be barred off. A significant proportion of rockfall accidents occur during re-entry after blasting, when the initial inspection and making-safe procedures are conducted to stabilise the rock before work recommences.

Generic workplace hazards generally relate to support conditions, ground conditions, inadequate escape ways or obstructions in escape ways, fire, exposure to unsafe electrical connections, humans in proximity of the area where loose rocks are to be barred, and working under unsafe roofs or sidewalls. These findings were corroborated by data collected from interviews with safety and health managers.

\subsection{Training environment and organisational aspects}

Training is done in accordance with the unit standards specified by the Mining Qualifications Authority. Most mines have training centres where new recruits are trained in job-related courses. This training is predominantly instructor-led and occurs in a classbased environment. In general, the use of technology in training is limited, but some mines do have computer-based training facilities. Class room training is usually followed up by practical training in the real work environment, until the instructor certifies the trainee as competent to perform the work correctly and safely.

Workers returning from annual leave, so called 'ex-leaves', go to the training centre for refresher courses before being permitted back in the underground milieu. A factor of concern is the lack of assessment after these refresher courses for ex-leaves. Sometimes workers merely sign a form indicating that they have worked through the files.

To accommodate high volumes of trainees, the use of nonimmersive systems on ordinary personal computers can provide a means of achieving current training goals. It is expected that as the technology gradually matures in this industry, facilities will be provided for more individualised systems to be developed and implemented, especially for training in the use of very expensive equipment such as the continuous miner or drill rigs.

Until very recently, sophisticated technology (such as VR simulations) for the training of highly skilled equipment operators was unavailable in the South African Mining Industry to train stereotypical employees (not to mention the illiterate). Although there is increased acceptance of the enormous changes in technology and its use, it is clear that the usual mine worker is very far removed from these technological advances. They are aware of them but they have very little-to-no opportunity of experiencing sophisticated technology and its benefits directly. Most of them have never touched a computer in their lives. 


\section{VR Training Prototypes}

It emerged from interviews with mine managers that improved and technologically advanced training systems are required to assist them to improve the safety records at their mines. Based on the findings regarding the contextual requirements and constraints for VR training systems, as well as analysis of previous accident statistics, various areas were selected for the development of VR prototypes, namely:

Generic hazard awareness in conventional mining.

Causes of ground falls.

Reconstructions of previous fatal accidents.

- Pedestrian and driver hazards regarding trackless moving machinery.

- $\quad$ Hazards related to smelting plant safety.

Due to the high volume of trainees and the unavailability of sophisticated immersive technology at mines, it was decided to develop non-immersive prototypes, that can run on standard personal computers. Should these prototypes subsequently be developed into training systems, they will be deployable on current computer training facilities at the mines. Initial prototypes were developed for the specific requirements of platinum and chrome mines.

\subsection{Hazard awareness}

A prototype training system called Look, Stop and Fix was developed to focus on hazard recognition and remedial actions. The prototype simulates the underground working areas, incorporating potential hazards that mine workers need to identify and indicating possible actions that might be followed in response to each hazard. Trainees must learn to spot these potentially hazardous conditions, identify the hazards correctly, and indicate which action/s should be taken to address the situation.

The contextual analysis provided valuable information to inform the design of the prototype. Based on this information it was decided that trainees would be placed in a $3 \mathrm{D}$ virtual underground environment, where the haulage and stope areas would be realistically simulated. Various generic hazards would be present in this environment, selected randomly from the five categories of hazards generated from the analyses as discussed in 6.2 (see Table 2).

In the Look, Stop and Fix prototype a camera pans slowly through the 'mine'. On the bottom of the screen a STOP button and a REPLAY button are visible. At any point in time, while the camera is moving through the mine, the trainee can use the mouse to click on any of the buttons. If the trainee clicks on REPLAY, the previous scene is replayed and there is another opportunity to view the environment. If the trainee clicks on STOP, the camera stops and two other buttons appear, GO and IDENTIFY.

Figure 1 is a screenshot from the prototype. (Note: In many of the figures, the screenshots appear dark. This is an accurate reflection of the actual underground work environment and the VR prototype was developed to portray realism).
H01: Rail gates not in position

H02 : Material stacked incorrectly on the material car

H03 : Loco blocks entry to working area

H04 : Short on electrical cable at substation

H05: Open explosive box

H06 : Loose rock falls on miner's head

H07 : Employee working in haulage gets run over by the loco

H08 : Employee falls over materials stacked incorrectly

H09 : Dangerous sidewall conditions

H10 : Mud-rush in haulage

H11 : Damaged support in waiting area

H12 : Pipes/Material stacked on the loco railway

H13 : Material is lying in the passage

H14 : Some segments on grizzly are missing

H15 : No drum guards on winch

H16 : Bad hanging wall

H17 : No barricade or chain around grizzly

H18 : Rigging not safe, snatch block hits miner

H19: Cover on lockout device is broken off

H20 : Not enough support at interconnecting brow and slip

H21 : Footwall area not cleared, misfire of explosives

H22 : Water spray hazard

H23 : Water in the area where people should walk

H24 : Excessive water

H25 : Employees are horse playing in the mine

H26 : Material stacked incorrectly in the haulage

H27 : Inadequate support in working area

Table 2. Generic hazards included in the prototype.

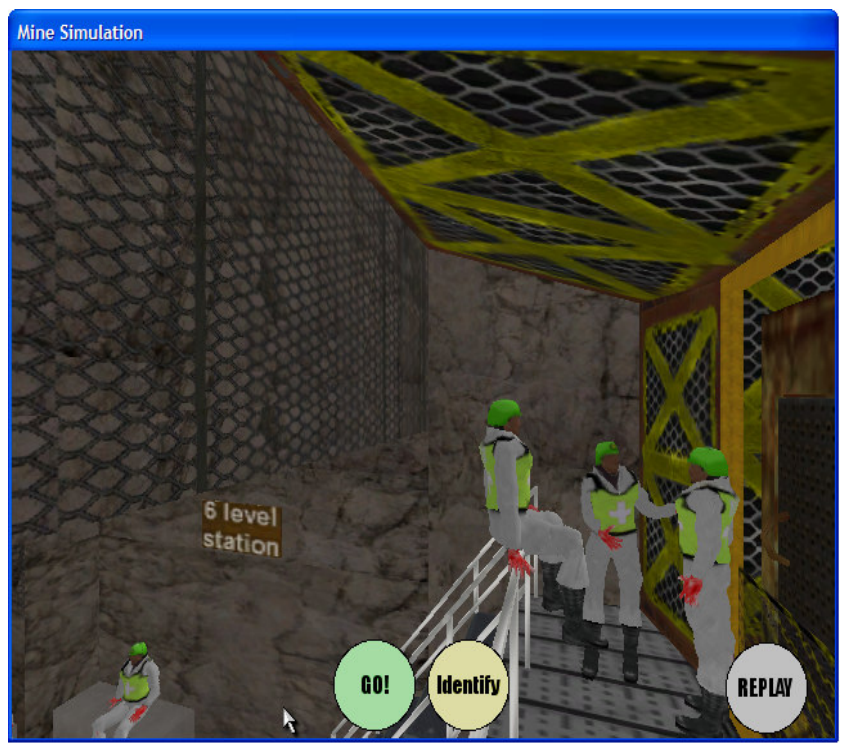

Figure 1. Screenshot of available options when trainee has stopped the simulation.

If the trainee is of the opinion that there is a hazard then the IDENTIFY button should be clicked. If not, clicking on GO will continue the simulation. If a hazard is present and the trainee clicks on IDENTIFY, then a number of possible hazards are shown and the trainee should select the appropriate one (see 
Figure 2). If the correct hazard is selected, then various remedial actions are shown and the trainee should select the correct option.

The simulation is in the form of a game and participants receive a score for each correctly-identified hazard as well as for correctly indicating the procedure to deal with each hazard. Different types of hazards have different score values. If the participant does not correctly identify a hazard or the correct procedure for dealing with it, an animation plays out displaying the possible disastrous consequences of ignoring such a hazard (see Figure 3).

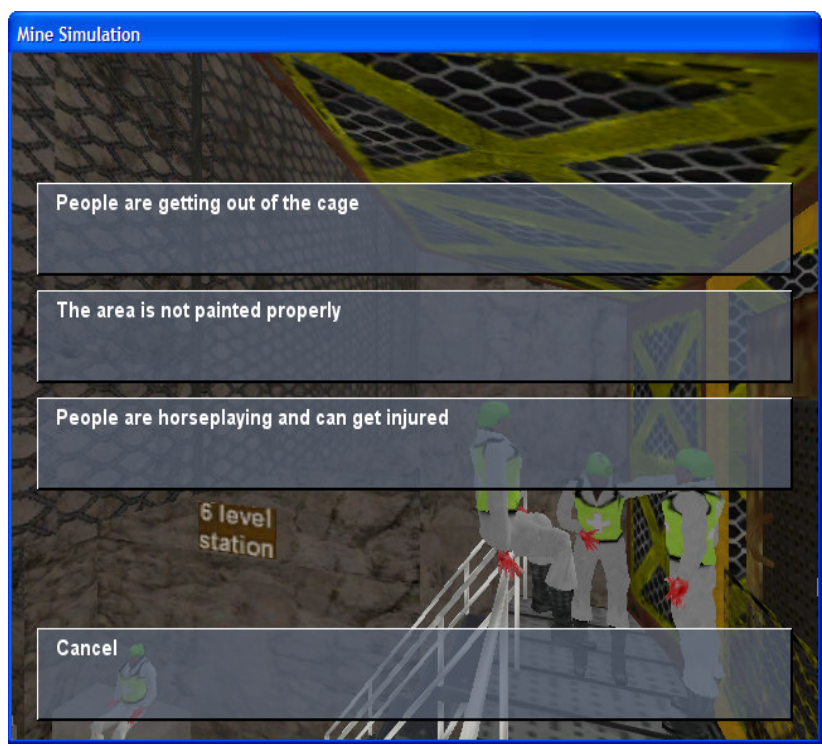

Figure 2. Example screen shot of options the trainee can select when identifying a hazard.

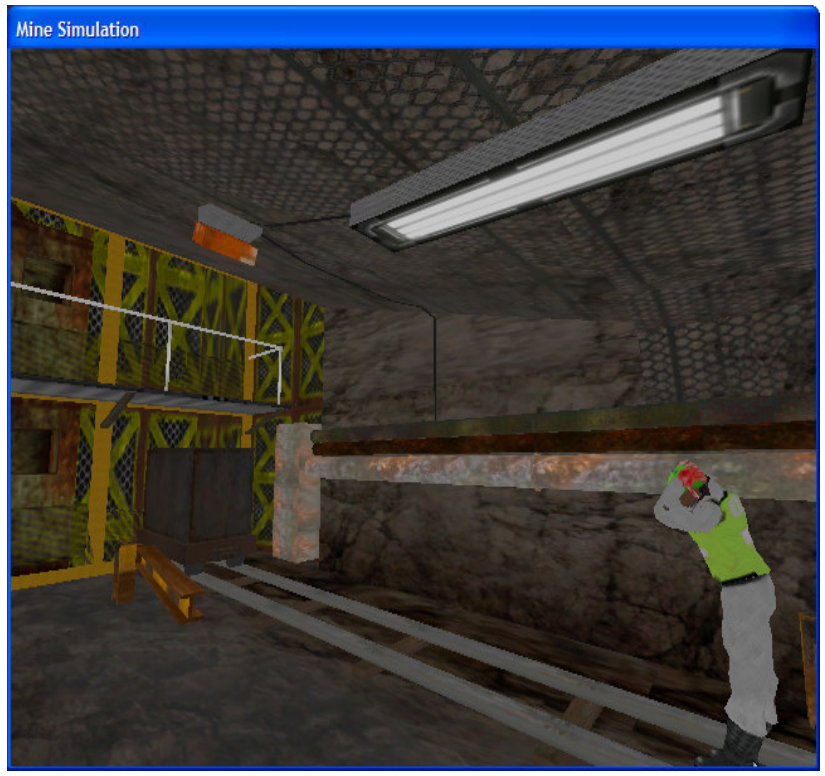

Figure 3. Animation of potential consequence of not closing the rail gate.

In the Look, Stop and Fix prototype trainees select their language of choice for use in the system. The options are English, Tswana, Sepedi and Xhosa. In the software the selected language is used throughout the simulation for any textual feedback. Participants can also hear the text in this language in audio mode via their earphones when the computer mouse cursor moves over the written text. Participants also receive feedback and explanations in the selected language.

\subsection{Ground falls}

Analysis of accident statistics reveals that the primary cause of fatal accidents underground is falls of ground (FOG). This is mainly due to incorrectly identifying and supporting various geological conditions prevalent after blasting. Another prototype was developed to simulate these geological conditions. In this prototype the trainee needs to identify the condition correctly and specify the associated risks and control measures for each condition. Cross section animations of geological conditions demonstrate the structure inside the hanging wall. This helps trainees to understand the dangers and threats associated with each condition by showing the invisible internal conditions.

A variety of geological conditions are simulated, including faults, shear zones, wedges, intersecting low angle joints, curved joints, dome structures and dykes (see Figure 4). As a camera slowly moves through the virtual environment, the trainee is presented with a virtual three-dimensional underground scene. The scene may/may not include a geological hazard. If the trainee spots a geological hazard, he presses the space bar on the keyboard and the camera is stopped. The trainee can also review the scene if he is unsure. In this prototype, as is the case with the LSF prototype, if the trainee does not correctly identify the hazard, a computer animation plays out depicting the possible results of ignoring such a hazard. He also receives feedback information on the hazard missed, using animation to show the general appearance of such a geological condition.

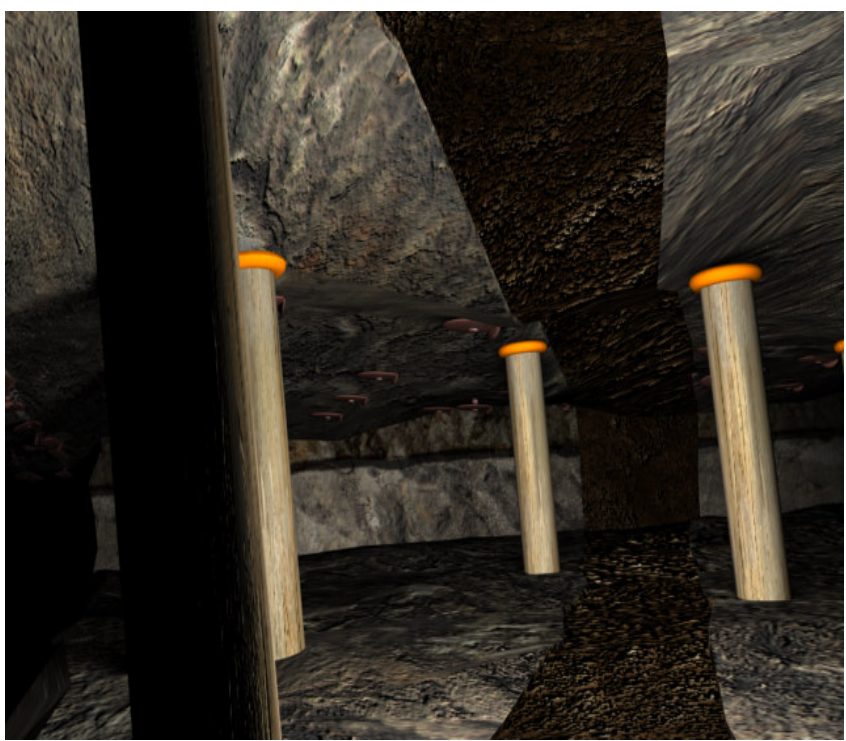

Figure 4. An incorrectly supported dyke condition. 


\subsection{Accident reconstructions}

The circumstances relating to previous serious accidents can be simulated to prevent recurrences. An animated Accident Reconstruction Simulation consists of the following components:

- A virtual environment with animated scenes depicting what occurred.

- Scenes indicating the cause/s of the accident by highlighting the erroneous actions undertaken.

- Scenes indicating the correct procedures for such circumstances.

As an example, Figure 5 indicates incorrect support of loose rock that caused the death of a miner.

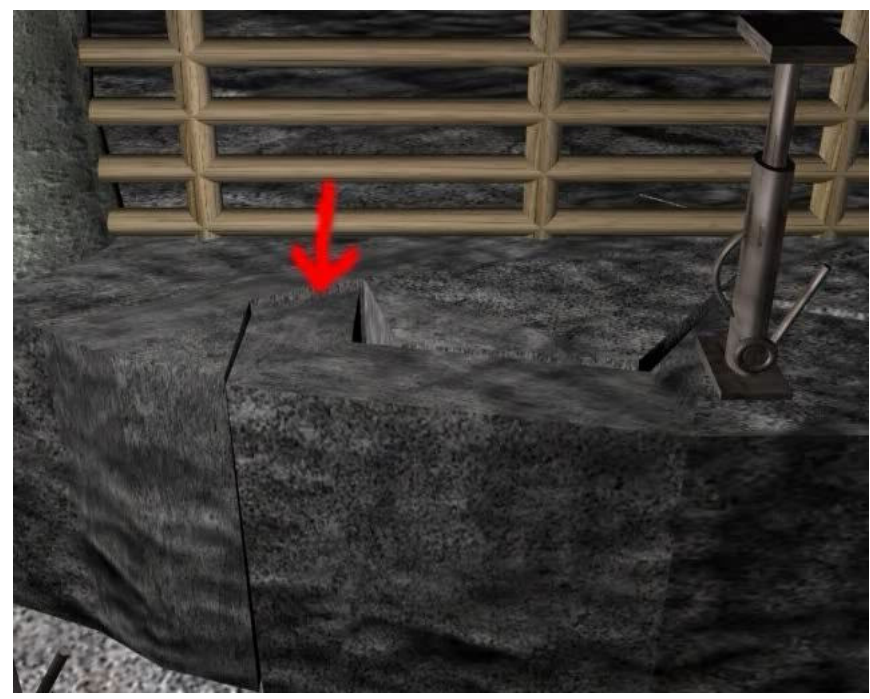

Figure 5. Accident Reconstruction Simulation: indicating the cause of accident.

\subsection{Trackless moving machinery}

A further prototype was designed to teach trainees the dangers and risks involved in moving machinery in the underground environment. A 'pedestrian' can be virtually placed in the simulated driver's seat, so that $\mathrm{s} / \mathrm{he}$ can experience and understand the driver's limitations with regard to restricted field of vision, maneuverability and vehicle control.

Figures 6 and 7 are screenshots from a virtual hazardous condition, where a mine worker, contrary to safety regulations, requested an LHD (Load-Haul-Dumper) driver to use the vehicle's bucket to lift him towards the hanging wall to replace a part on a fan. The driver accidentally lifted the bucket too high and crushed the mine worker against the hanging wall.

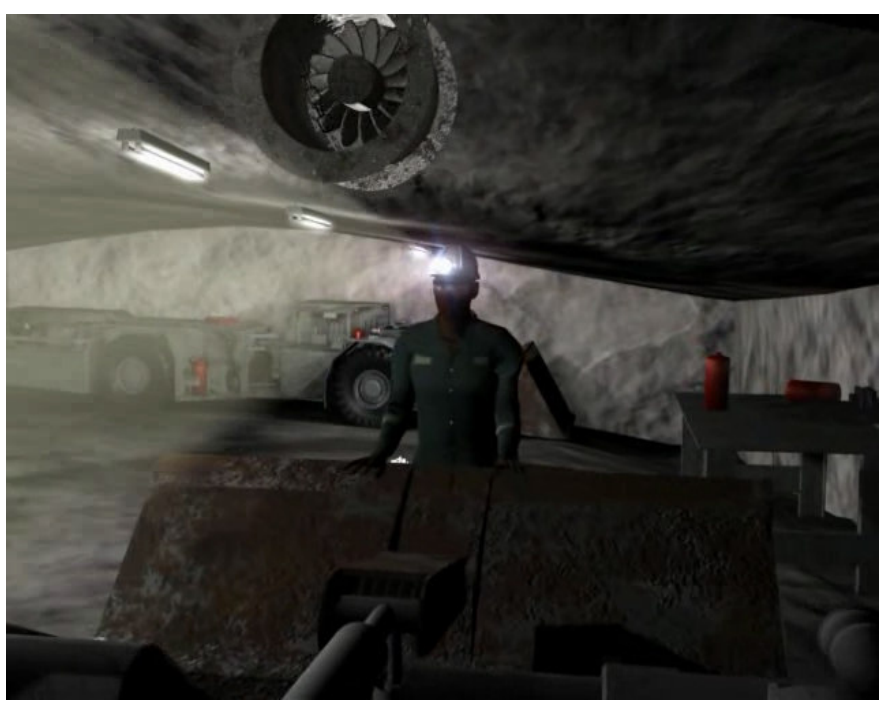

Figure 6. Mine worker waiting to be lifted from inside the LHD bucket.

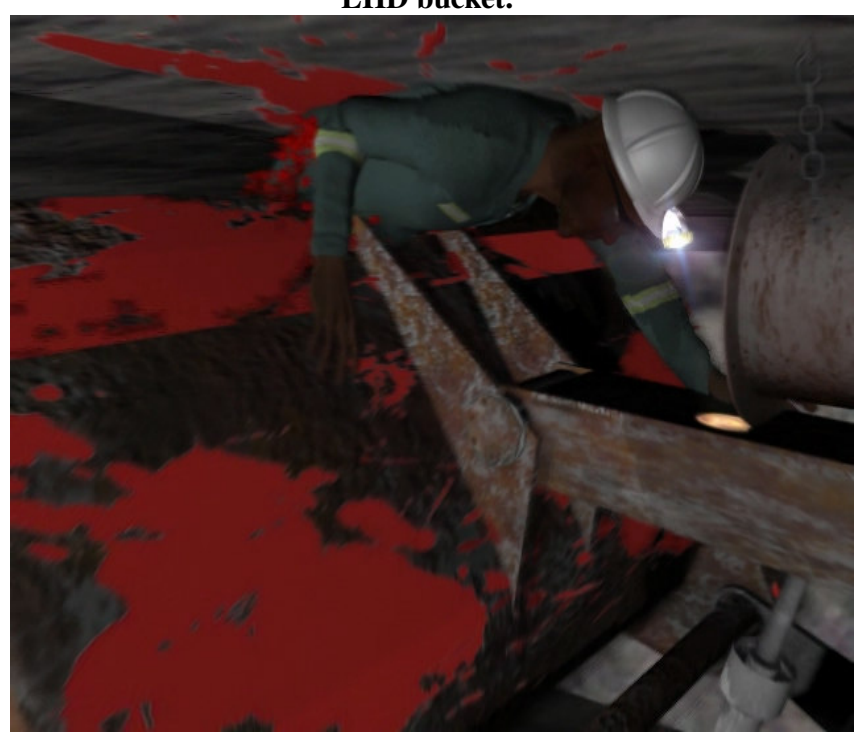

Figure 7. Mine worker crushed by the LHD bucket.

\subsection{Hazards at smelting plants}

This prototype simulates hazardous conditions within the particular context of a chrome smelting plant. It is aimed at testing the trainee's ability to identify unsafe work practices and physical condition exposures that may be prevalent in their daily work environment. It assists trainees in the practical application of newly-attained conceptual knowledge of best practices and physical condition requirements in such a plant. 


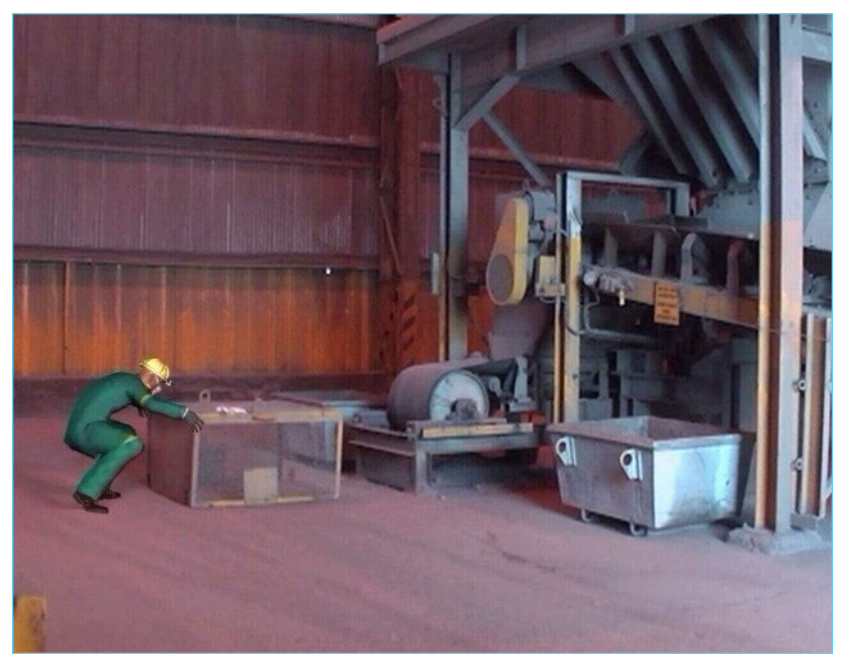

Figure 8. Worker removing the drum guard while conveyor is running.

Figure 8 shows a worker removing the protective conveyor drum guard without stopping and locking out the conveyor, as is required by the safety procedure. This prototype is an example of augmented reality, where computer animation is overlaid on video footage of the actual conveyor.

A traffic light is used as metaphor. The objective is for the trainee to correctly identify why it is a 'red' condition and to change the situation to green by correctly answering questions on how to deal with a particular scenario. A virtual environment portraying a specific substandard condition is shown to the trainee and he/she must correctly identify the condition by choosing the right answer from the available options. The traffic light can be turned to green by correctly identifying the substandard condition and by specifying how it should be treated.

\section{Enhancing realism}

It is essential to capitalise on the wide-ranging capabilities of computing in order to maximise realism within training systems. This contributes to the authenticity and impact of the simulated trainee experience. In mining prototypes, realism can be addressed on three levels:

\subsection{Realism in computer-generated imagery (CGI)}

In the development of VR systems, realism can be enhanced by:

- Using motion capture systems: Motion capture is the process of recording movement and translating such movement onto a digital model. Complex movements and realistic physical interaction in the underground mining environment can be easily recreated in a physically accurate manner. Motion capture provides a degree of realism that could be very challenging and time-consuming for animation developers to create by just using animation software tools.
- Using augmented reality: Virtual environments are created by $3 \mathrm{D}$ models of the real world. Using augmented reality or mixed reality (as shown in Figure 8) can enhance realism by adding photo or video images of the real environment to the CGI.

\subsection{Realism in content}

The content of e-training applications should be realistic with regard to the coverage of job-specific learning material. In certain situations, the presentation sequence of material can be randomized, but in other cases, it is important to maintain a fixed sequence. Such cases might include virtual environments where the trainee will 'move' from a certain position in the mine to another position, e.g. walking through the haulage to the stope. This approach is also required when a procedure should be conducted step-wise, e.g. stope entry procedure after blasting. Furthermore, the training material should be realistic in terms of the current standards applicable to the underground situation at the specific mine, e.g. distances between roof bolts or timber supports.

\subsection{Realism in experience}

Realism in the trainee's experience of the virtual environment can be enhanced by:

- Increased levels of immersion, e.g. stereoscopic projection. Stereoscopic panoramic environments can be used to immerse an audience in 3D imagery. Such a system could include a vision-based motion tracking system capable of tracking and responding to movements of users. Stereoscopic projection onto a dome structure can also be used for spherical representations to cover the peripheral vision of a user standing directly in front of it. This can result in a truly immersive experience. Stereoscopic glasses allow the simulations to be seen in $3 \mathrm{D}$ and panoramic screen projection enables a group of miners to experience simulations with an incredible degree of realism. Trainees can be confronted with highfidelity representations of real-world problems.

- The generation of virtual environments where teamwork is emphasized. Because work underground is performed in teams, it should be imperative to provide a simulated training environment in which a team can work together as a unit. Semi-immersive systems using stereoscopic projection or immersive systems can cater for this need.

Developing more realistic CGI, e.g., rather than the creation of virtual environments of "a" mine, the developers of the virtual environment should attempt to generate "their" mine.

\section{Conclusions}

The various VR prototype systems were installed and used at mines and smelting plants. They were all well received and provided an interesting and engaging alternative to conventional training programmes. Simultaneously, the approach improved the safety culture and awareness of the workforce. 
Evaluation of the Look, Stop and Fix prototype was undertaken at a large platinum mine (Van Wyk, 2006) and more than $80 \%$ of the miners indicated in post-assessment questionnaires that they enjoyed this training a lot, that they felt this type of training is better than lectures or videos and that the system helped them to learn a lot. Full-scale evaluations of the other prototypes will be undertaken in the near future.

In terms of realism, participants were asked if they thought the hazards included in the system could really happen. Most participants felt that all the hazards portrayed were real hazards in their working environment. It is interesting to note that in a follow-up question whether the accidents in the system could actually happen to them, many thought most of them would not. This could be because of their particular jobs that some hazards would not be a threat to them but it could also be an indication of an attitude that accidents are more likely to happen to others than to themselves.

The introduction of VR training systems to the mining industry, similar to the prototypes discussed in this paper, offers potential advantages:

- They are a low-cost alternative to creating full-scale, real-life training scenarios.

- Systems can be designed to be multilingual, and trainees can be taught in their mother tongue.

- VR is a flexible configuration, and is open to ongoing modification and customization.

- It offers an opportunity to create a wide variety of scenarios, including ones rarely or never previously encountered in real life.

- It exposes users to simulated situations that would be dangerous to encounter in real life.

- This virtual "time on task" experience helps reinforce the learning that took place during the conventional classroom instruction.

- The VR training systems provide appropriate levels of trainee interaction.

- Trainers can review trainee's records from an extensive database, compare results and generate graphs of performance of individuals or groups.

- Trainee problem areas are easily identifiable.

With reference to the taxonomy of interactive computer-based visualization systems, as discussed in section 3, the VR prototypes described in this paper were class 1 and class 5 systems. Future work will focus on the introduction of training systems that are more immersive and with enhanced realism, specifically systems as described in classes 6 and 7 which also cater for group participation. Other areas for future system development have already been identified and include isolation procedures, systematic supervision, conveyor procedures, winch operations and emergency evacuation procedures.

From the perspectives both of trainees and management within the target sites, it was indicated that virtual reality training is viable and advantageous for the South African mining industry. The approach is likely to be transferable to the broader African context.

\section{Acknowledgements}

We would like to thank all the participants in this study. We appreciate the invaluable help of the mine managers and SHE managers for participating in personal interviews. The expertise of the students at the Centre for Creative Technologies at TUT, who assisted in developing the prototypes, is gratefully acknowledged.

\section{References}

BAKER, D. 2005. Interview with Safety, Health and Environment Manager, Anglo Platinum Bafokeng-Rasimone, (notes in possession of researcher).

BISE, C. J. 1997. Virtual Reality: Emerging Technology for Training of Miners, Mining Engineering, 49(1).

Denby, B., Schofield, D., McClaron, D. J., Williams, M.W., AND Walsha, T. 1998. Hazard Awareness Training For Mining Situations Using 'Virtual Reality'.

Denby, B., AND Schofield, D. 1999. Role of Virtual Reality in Safety Training of Mine Personnel. Mining Engineering, October:59-64.

De Strulle, A. 2004. Differentiation of the Causal Characteristics and Influences of Virtual Reality and the Effects on Learning at a Science Exhibit, PhD Thesis, University of San Diego.

DEPARTMENT OF Minerals AND ENERGy. 2005. Guideline for Enforcement of the Mine Health and Safety Act [Online]. Available from:

http://www.dme.gov.za/publications/pdf/guidelines/guideline_e nforcement_mhs_act.pdf. [Accessed: 22/12/2006].

DePARTMEnT OF Minerals AND ENERGy. 2006. Accident Statistics [Online]. Available from:

http://www.dme.gov.za/mhs/accident_stats.stm.[Accessed: 20/07/2007].

DePartment of Minerals AND EnERgy. 2008. SAMRASS [Online]. Available from:

http://www.dme.gov.za/pdfs/mhs/samrass/cb_sect_e.pdf.

[Accessed: 16/06/2008].

Le Roux, A. 2005. Mine fatalities down, but still too high. Mining Weekly [Online]. Available from:

http://www.miningweekly.co.za/min/features/health/?show=665 81 [Accessed: 12/06/2006].

LubBE, O.S. 2006. Interview with Chief Executive, Chrome Mining Division, XSTRATA Alloys, Rustenburg, (notes in possession of the researcher).

Milgram, P., AND Kishino, F. 1994. A Taxonomy of Mixed Reality Visual Displays. IEICE Transactions on Information Systems, Vol E77-D, No.12 December.

Mine Health And Safety Act. 1996. Act No. 29 of 1996 [Online]. Available from: 
http://www.polity.org.za/html/govdocs/legislation/1996/act96029.html [Accessed: 22/04/2007].

MoldenhaueR, R. 2004. Interview with Safety, Health and Environment Manager, Anglo Platinum Lebowa, (notes in possession of the researcher).

ORR, T.J., FiligenZI, M.T., AND RufF, T.M. 2002. Desktop Virtual Reality Miner Training Simulator [Online]. Available from: www.cdc.gov/niosh/mining/pubs/pdfs/dvrmt.pdf. [Accessed: $12 / 01 / 2007]$

SCHMID, M. 2003. Virtually Assured - the role of virtual reality in the field of coal mining. World Coal, No. 11, pp. 45-48

SchofIeld, D., Denby, B., AND Hollands, R. 2001. Mine Safety in the Twenty-First Century: The Application of Computer Graphics and Virtual Reality, In Mine Health and Safety Management, ed. Michael Karmis. Littleton, Colorado: SME, Chapter 10, pp. 153-174, November 2001.

SQUELCH, A.P. 2000. VR as an industrial training and marketing tool. Conference Proceedings IFIP 2000 [Online]. Available from: www.irv.ufsc.br/IFIP-WG-9.5/proceedings. [Accessed: 12/04/2008].

SQUELCH, A.P. 2001. Virtual reality for mine safety training in South Africa. J. S. Afr. Inst. Min. Metall., 101(4). SAIMM, Johannesburg.

Stander, D. 2005. Interview with Mine Manager Anglo Platinum Lebowa, (notes in possession of the researcher).

Stothard, P.M., Otto, D., Laurence, D.C., Galvin, J.M., Zenari, L. 2001. e-minesafe Safety and Training Simulator "The Integration of Knowledge and Skills to Achieve Safe Human Responses" UMRC Research Report RR10/01 ISBN No. 0733418449.

Stothard, P. 2007. Developing and Deploying and Deploying Interactive Training Simulations for the Coal Mining Industry. Proceedings SIMTECT 2007.

Stothard, P.M., SQuelch, A.P., VAN WyK, E.A., Schofield,D.,Fowle, K., Caris, C., Kizil, M., ANd Schmid, M. 2008. Taxonomy of Interactive Computer-based Visualisation Systems and Content for the Mining Industry - Part 1, Proceedings of the AUSIMM Future Mining Conference 2008, Sydney.

Unger, R., And Mallet, L. 2007. Virtual Reality in Mine Training, in SME Annual Meeting and Exhibit, February 25-28, Denver, Colorado, Society for Mining, Metallurgy, and Exploration.

VAN WyK, E.A. 2006. Improving Mine Safety Training Using Interactive Simulations. In Proceedings of the ED-MEDIA 2006 World Conference on Educational Multimedia, Hypermedia and Telecommunications 2006: 2454-2459. Orlando, Florida.
Van Wyk, E.A., AND Callaghan, R. 2007. E-learning as a solution for mine safety training in South Africa, Proceedings of Online Educa Berlin 2007.

Wenhold, M. 2005. Interview with Safety, Health and Environment Manager, Impala Platinum Rustenburg, (notes in possession of the researcher). 
